\title{
Experiment Teaching Innovation of the Course Computer Hardware Fundamentals
}

\author{
Chunhua Fang, Zhendi Wu \\ Department of Electrical Engineering, Tongji University, Shanghai, China \\ Email: chunhua fang@163.com
}

Received January 2014

\begin{abstract}
The course Computer Hardware Fundamentals to non-electrical engineering students aims to teach the basic principles and applications of microcomputers so that the students could use computers to solve practical problems in professional or related fields. The teachers have to face the fact that the current experiment teaching cannot meet the demand of students because of less class hour. Based on the analysis of a questionnaire which focuses on the students' expectation of the experiments as well as the problems existing in the current experiments, a new general elective experimental course "Computer hardware Technology Fundamental Application Experiments" is put forward, and some innovative experiment teaching content and methods are introduced in this paper.
\end{abstract}

\section{Keywords}

\section{Experiment, Computer, Hardware Fundamentals, Innovation}

\section{Introduction}

Implementing the guiding ideology of the National Ministry of Education that basic computer education in colleges and universities is divided into three levels, the course Computer hardware fundamentals is one of the second level courses offered in Tongji University, which aims to teach the basic principles and applications of microcomputers so that the students could use computers to solve practical problems in professional or related fields.

\section{History of Curriculum Reform}

Computer Hardware Fundamentals was formerly known as the subject Microcomputer Principle and Interface Technology to non-computer engineering students. The subject was divided into two courses in 1998, one is still Microcomputer Principle and Interface Technology to electrical engineering, the other is Computer Hardware Fundamentals to non-electrical engineering.

The teaching content of Computer Hardware Fundamentals had been modified in 2000. The traditional content of microcomputer principles, interfaces and applications apparently are not easy to understand by non-electrical students though they are appropriate for electrical engineering students. 
In 2002, considering the students coming from different specialties and different grades, with different learning backgrounds, in order to adapt to the changes in teaching, the teaching staff had put forward a proposal to highlight the basic concepts and applications, as well as the current mainstream technology. And from then on, Computer Hardware Fundamentals has been positioned a basic public course to non-electrical specialties.

\section{Current Experiment Teaching Status and Problems}

Students of Computer Hardware Fundamentals covers varieties of specialties of arts, science, and engineering (post-2012 mainly in art, science majors based), however, the nature of basic computer courses make the course cannot take care of professional requirements. Less experiment hours are assigned to because of less course hours (32 class hours). The experiments are simple interface operations on a computer hardware experimental box, mainly about audio application and LED display by calling some given assembly programs. However the students of freshmen or sophomores can't understand the hardware experimental box which only shows some interface/hole to the users, and they don't know assembly language, so it's undoubtedly that the students are not interested in the experiments. Thus the experimental program is unable to achieve the aim of the teaching syllabus required.

\section{Analysis of Current Experiment Teaching Status Questionnaire}

To carry out the experiment teaching reform, in view of the existing experiment content, an anonymous questionnaire was conducted to learn students' view of the current experiment content and their desired computer hardware technology foundation experiments.

\subsection{Investigation Questionnaire and Statistics of the Results}

The questionnaires were collected from 79, statistical results are as follows (Table 1).

\subsection{Analysis of the Questionnaire Result}

The questions of the questionnaire are settled mainly from the students' expectation of the experiments as well as the problems existing in the current experiments.

The answers of question NO.4 and NO.5 show the main confusion of students when they have experiments of Computer Hardware Fundamentals, that is lack a certain knowledge of assembly language, and $76 \%$ of the students feel it is the difficult part of the experiment that they don't understand the executive function programmed in assembly language. Because the students only need to call a given program to drive the speaker or display, etc. Most of them may finish the experiment quickly but still don't know exactly which statements implement these functions, how to modify the program to achieve some other functions. That is to say, they are still obscure to the experiment. So explain some necessary assembly statements, procedure and principle of the program will be of great help.

In question (2), almost $90 \%$ of the students in favor of using "program application + part of programming" mode of experiment, shows that most students want to know the basic assembly language, and like to try programming. There are also some related suggestions in the last open questions: "Knowledge of assembly language is not enough, can't understand the given program well."; "Introduce the assembly language first, otherwise cannot read the program." Thus, part of the assembly language knowledge is needed to be taught in the experiment teaching; There had better have detailed annotations of the main function modules or key statements in the program; at the same time, some statements filling up can also be designed to let the students understand the program step by step.

In question (1), more than half of the students choose to do applied experiments. In question (6), $61 \%$ of the students valued ability of operation, which was also reflected in the last open questions: "increase practical experiments", "to the practical direction." these illustrate that the basic experiment of computer hardware technology should focus on "application", which is current experiments lack.

In question (7), more than half of the students are interested in "computer disassembling and assembling experiment", "hard disk data recovery" and "computer fault diagnosis" respectively. This suggests that the students hope to understand the computer hardware through "anatomical type of learning", and learn computer fault diagnosis through the experiment. Summarize the whole questionnaire, the design of Computer Hardware 
Table 1. Statistics of the questionnaire results.

\begin{tabular}{|c|c|c|}
\hline 1) Which of the following types of experiment do you hope to do? & Number of people & percentage \\
\hline verification type & 19 & $24 \%$ \\
\hline design type & 20 & $25 \%$ \\
\hline applied type & 40 & $51 \%$ \\
\hline \multicolumn{3}{|l|}{$\begin{array}{l}\text { 2) Which of the following experimental mode of Computer Hardware Fundamentals } \\
\text { would you like to take? }\end{array}$} \\
\hline program application + part of programming & 71 & $90 \%$ \\
\hline programming & 6 & $8 \%$ \\
\hline others_ & 2 & $2 \%$ \\
\hline \multicolumn{3}{|c|}{ 3) Do you think it is necessary to reform the experiment of Computer Hardware Fundamentals? } \\
\hline Yes & 56 & $71 \%$ \\
\hline No & 23 & $29 \%$ \\
\hline \multicolumn{3}{|l|}{$\begin{array}{l}\text { 4) What's the main difficulty when you having the experiments of } \\
\text { Computer Hardware Fundamentals? }\end{array}$} \\
\hline insufficient knowledge of assembly language & 60 & $76 \%$ \\
\hline lack of preparation & 13 & $16 \%$ \\
\hline the experiments are too complicated & 1 & $1 \%$ \\
\hline failed to interest & 5 & $7 \%$ \\
\hline \multicolumn{3}{|l|}{$\begin{array}{l}\text { 5) Which of the following conditions do you think is needed to do experiments of } \\
\text { Computer Hardware Fundamentals well? }\end{array}$} \\
\hline know some assembly language & 36 & $46 \%$ \\
\hline preliminary understanding the process and principle of experiment & 32 & $41 \%$ \\
\hline set questions and part design the experiment & 11 & $13 \%$ \\
\hline \multicolumn{3}{|l|}{$\begin{array}{l}\text { 6) Which of the following do you think is more important view of the experiments } \\
\text { of Computer Hardware Fundamentals? }\end{array}$} \\
\hline improve operating ability & 48 & $61 \%$ \\
\hline logic thinking skill & 29 & $37 \%$ \\
\hline other aspects ability (can be added) & 2 & $2 \%$ \\
\hline \multicolumn{3}{|c|}{ 7) Which of the following development experiments are you interested in? (multi-choices) } \\
\hline computer disassembling and assembling & 43 & $54 \%$ \\
\hline network cable making and connectivity test & 23 & $29 \%$ \\
\hline hard disk data recovery & 42 & $53 \%$ \\
\hline USB disk senior operation & 33 & $42 \%$ \\
\hline computer fault diagnosis & 40 & $51 \%$ \\
\hline keyboard and mouse disassembling and assembling & 14 & $18 \%$ \\
\hline \multicolumn{3}{|c|}{ 8) Could you give some advice of “computer hardware fundamentals experiment reform direction”, or point out the deficiency. } \\
\hline \multicolumn{3}{|l|}{ Teaching the experiments with multimedia PPT. } \\
\hline \multicolumn{3}{|l|}{ Increase practical experiments. } \\
\hline \multicolumn{3}{|c|}{ Improve the hardware facilities, such as the mouse is very difficult to use. } \\
\hline \multicolumn{3}{|c|}{ Knowledge of assembly language is not enough, can't understand the given program well. } \\
\hline \multicolumn{3}{|l|}{ More fun. } \\
\hline \multicolumn{3}{|l|}{ To the practical direction } \\
\hline Introduce the assembly language first, otherwise can & am. & \\
\hline
\end{tabular}

Fundamentals experiments needs to accord with the application requirement of the students, to enhance the applicability of experiments, is not only stay on the experiments done on the experiment box.

\section{Exploring Innovative Experiment Teaching}

According to the position of the course, "Computer Hardware Fundamentals” is a practical technology founda- 
tion course. As a result of less class hour, in order to make the students really understand the computer hardware infrastructure, to achieve the teaching goal through the experiments of "have strong practical ability and scientific research and development ability", we decide to open a new general elective experimental course "Computer hardware technology fundamental application experiments" without affecting the original teaching program.

\subsection{Experiment Teaching Content Reform}

The course "Computer hardware technology fundamental application experiments" is based on PC hardware platform, and all the experiments are designed on the basis of research, which is a series of applied experiments that the students are interested in. Through anatomical type of experiment teaching to computer hardware, to consolidate and deepen the understanding of the theoretical study of computer hardware, to improve hands-on practice and innovative ability, and to lay a certain foundation for learning the follow-up professional courses and the future work in engineering technology. The course preset 16 experiments, which cover the computer assembly and debugging, common computer fault diagnosis, computer hardware test, optimization of computer system and safety protection, U disk senior operations, network fault diagnosis and maintenance, integrated application experiments of computer, etc. These experiments are closely related to the students' daily computer application, thus widely welcomed by them [1].

In the integrated application experiments, through simple assembly language programming, the students will understand that computer hardware technology and software technology complement each other. Use DEBUG to deepen the understanding of theoretical knowledge, students will be familiar with the way data stored in the memory and operand addressing mode, have more specific understanding of the structure and principle of memory, and thus can more accurately find errors in the program. Through development experiments of the interface, students will "see through" the principle, method and application of input and output interfaces. Through experiments of display on PC screen, students will be delighted to see their design performance, experience the pleasure of "achievement".

\subsection{Innovative Experiment Teaching Methods}

Appropriate way of teaching is the necessary condition to achieve good teaching effect. Computer hardware technology fundamental application experiments teaching combine theory and practice closely through theoretical explanation and practical operation at the same time. The students are taken as the main body in the process of teaching; the "one-way infusion" teaching mode is changed to heuristic, discussion-based teaching and learning. Experiment problems are solved step by step through group study, discussion and practice, and then shared with the class. Teachers continue to inspire questions, set up difficulties in the class through a planned way, guide students to think, mobilize the enthusiasm of their learning, and to deepen understanding of the issues by constantly asking questions and solving problems. Furthermore, it's positive to organize students to actively take part in all kinds of computer knowledge lectures and competitions [2].

Modern teaching methods provide a great help to achieve good teaching. In traditional experiment teaching, the teacher explains the procedure of the experiments and the use of the instruments in front of the classroom, the students are crowded to watch, some can see what the teacher taught, some can't see. The first point in the open questions of the questionnaire is mentioned "Teaching the experiments with multimedia PPT". Therefore, teachers can use CAI technology to express some content which is laborious, not easy to understand, such as the experimental principle, operation of the instruments, etc. Multimedia technology help the experiment teaching to get more vivid and rich information through text, sound, graphics, images, and animation. And through course website, the students can get more free space to accept knowledge and related course materials online.

\section{Conclusion}

In case of insufficient teaching hours (32 hours), how to optimize the theoretical teaching content, and strengthen the experiment teaching, to " equip students with the ability that use computers to solve practical problems in related fields" that the course "Computer Hardware Fundamentals" requires, open a general class of elective course "Computer Hardware Technology Fundamental Application Experiments" is a recommended solution. The course has just started, however, is still at the exploration stage, and still need the teacher constantly think- 
ing and improve in practice.

\section{References}

[1] Song, T. and Li, F.X. (2010) Innovation in the Experiments for Computer Hardware Fundamentals. Journal of Computer Education, 17, 65-68.

[2] Wang, X.L. and Zhu, L.Z. (2007) Exploring Course Improvement of Computer Hardware Fundamentals. Journal of China University of Petroleum (Edition of Social Sciences), 8, 104-105. 